\title{
AS REPERCUSSÕES DAS CONDIÇÕES CRÔNICAS DE SAÚDE NA FAMÍLIA
}

\section{THE REPERCUSSIONS OF CHRONIC HEALTH CONDITIONS IN THE FAMILY}

\section{Bruna Sodré Simon ${ }^{1} *$ Raquel Pötter Garcia ${ }^{2}$}

A transição demográfica e epidemiológica no Brasil tem demonstrado uma redução no quantitativo de condições agudas de saúde e elevação nas condições crônicas. Essas, em sua maioria, são imprevisíveis, apresentam progressão lenta, multicausalidade e potencial para perda funcional com o decorrer do tempo ${ }^{(1)}$.

Nossas vivências e experiências, enquanto enfermeiras, docentes e pesquisadoras, corroboram para o entendimento de que as condições crônicas de saúde têm repercussões na família. Essa perspectiva vai ao encontro da compreensão de família como um sistema ${ }^{(2)}$, formado por subsistemas individuais, correspondentes aos seus membros e, por um suprassistema, representado pelas relações de amizade, de trabalho e demais componentes da sociedade com os quais interagem.

Por ser um sistema interligado, quando um componente do núcleo familiar é acometido por uma condição crônica, há repercussões no restante da família. A intensidade desse evento para cada um irá depender das relações, papéis e funções estabelecidas dentro da família ${ }^{(2)}$, além do significado atribuído a essa realidade. Mediante essa situação, que desestabiliza a rotina e a dinâmica, a família busca, de algum modo, uma mobilização para atender às demandas frente ao adoecimento crônico para evitar o desenvolvimento de novos desfechos inoportunos. Para isso, muitas vezes, ocorre a inversão de papéis, modificações nas relações e planos familiares, privações sociais, mudanças estruturais no domicílio, dentre inúmeras outras possibilidades que as famílias identificam como significativas para atender suas necessidades diante do contexto de instabilidade.

A focalização na família, diante do adoecimento crônico, propõe considerá-la como sujeito do cuidado, dentro das múltiplas terapêuticas, exigindo uma interação da equipe de saúde com essa unidade social e o conhecimento integral de seus problemas de saúde e das suas singularidades para uma adequada intervenção familiar ${ }^{(1)}$. É preciso ultrapassar a condição hierarquizada de saberes e evoluir para o cuidado compartilhado, de comunicação clara, objetiva e esclarecedora, capaz de envolver as diferentes perspectivas das famílias e dos profissionais, com objetivo de fortalecer a família como unidade cuidadora.

No entanto, apesar da produção do conhecimento acerca dessas questões estar consolidada no ambiente científico, por que ainda identificamos um cuidado inadequado com as pessoas acometidas por condições crônicas e suas famílias nos serviços de saúde? Esse questionamento, em parte, é respondido com base em um sistema de atenção à saúde focado em atender eventos agudos, de forma "fragmentada, episódica e reativa"(1). Também, como complemento à resposta do questionamento, destacamos o processo formativo em saúde: Apesar de constantes avanços, novos direcionamentos e discussões para atualização das

\footnotetext{
${ }^{1}$ Enfermeira. Doutora em Enfermagem. Docente do Curso de Enfermagem da Universidade Federal do Pampa (UNIPAMPA), Campus Uruguaiana, Rio Grande do Sul, Brasil. Vice-Líder do Núcleo de Estudos em Família e Cronicidade (NEFAC/UNIPAMPA). Membro do Grupo de Pesquisa Cuidado, Saúde e Enfermagem - Núcleo de Estudos em Cuidado e Família (NECFAM/Universidade Federal de Santa Maria). E-mail: brunasimon@unipampa.edu.br ORCID: 0000-0003-3855-1310

${ }^{2}$ Enfermeira. Doutora em Ciências. Docente do Curso de Enfermagem da UNIPAMPA, Campus Uruguaiana, Rio Grande do Sul, Brasil. Líder do NEFAC/UNIPAMPA. E-mail: raquelgarcia@ unipampa.edu.br ORCID: 0000-0002-5503-7981
} 
diretrizes curriculares em saúde, na prática, ainda está fortemente arraigado em um modelo reducionista, com foco na doença, o que contribui para ações individuais mesmo dos profissionais recém-formados.

Mas então, o que fazer para modificar essa realidade? É preciso pensar família e fomentar a abordagem e inclusão desse grupo social nos mais diversos espaços, instigando que o cuidado seja realizado com a família e de acordo com as representações e os significados das suas necessidades. Além disso, a pesquisa e o ensino devem estar em consonância com os serviços de saúde, suscitando ações que promovam de fato a inclusão da família, bem como a transposição do conhecimento científico para a prática assistencial.

Assim, são requeridas mudanças tanto no processo formativo quanto na educação permanente nos serviços de saúde. É necessário transversalidade curricular da temática nas escolas formadoras, não somente em Cursos de Enfermagem. Para, assim, fortalecer a Enfermagem da Família e também todos os cursos da área das ciências da saúde, uma vez que as repercussões das condições crônicas de saúde nas famílias são diversas e exigem profissionais dos diferentes núcleos de atuação capacitados para ofertar um cuidado compartilhado com a família e não para a família. No cenário assistencial, precisamos conhecer e identificar quem é a família e discutir abordagens conjuntas, nas quais os seus integrantes sejam ativos durante todo o processo.

Por fim, entendemos que os profissionais de saúde têm um papel importante de ajudar as famílias para a organização do cuidado, de modo que consigam encontrar maneiras de se adaptar e/ou superar as adversidades. E ainda, minimizar os aspectos negativos que possam surgir em seu contexto diante da processualidade emergente do convívio com uma condição crônica.

\section{REFERÊNCIAS}

1- Mendes EV. O cuidado das condições crônicas na atenção primária à saúde: o imperativo da consolidação da estratégia da saúde da família. Brasília: Organização Pan-Americana da Saúde; 2012.

2- Wright LM, Leahey M. Nurses and families: a guide to family assessment and intervention. Philadelphia, Pennsylvania: F. A. Davis Company; 2019.

Autor correspondente

Bruna Sodré Simon. Endereço: BR 472, KM 585, Caixa Postal 118, Uruguaiana, Rio Grande do Sul, CEP 97501-970. Telefone (55) 999787902 E-mail: brunasimon@unipampa.edu.br 